\title{
FIANDO A TAPEÇARIA EM UM FIM DE TARDE: UMA DISCUSSÃO SOBRE O FIM E O PRINCÍPIO
}

\author{
SPPINING THE TAPESTY IN THE EVENING: \\ A DISCUSSION ABOUT O FIM E O PRINCÍPIO
}

DOI: http://dx.doi.org/10.15448/2178-3748.2018.1.24471

\author{
Fábio Ronaldo da Silva \\ Doutor em História - UFPE \\ fabiocg@gmail.com \\ Paulo Roberto Souto Maior Júnior \\ Doutorando em História - UFSC \\ paulosoutom@gmail.com
}

RESUMO: Este artigo objetiva discutir questões relacionadas à velhice tendo como fonte o documentário $O$ fim $e$ o princípio (2005), do cineasta Eduardo Coutinho. O documentário traz um conjunto de histórias aparentemente aleatórias e contadas por idosos. O espaço escolhido pelo diretor para "coletar" esses relatos é a Paraíba. Partimos dessa produção para escrever outra trama que envolve a reflexão entre a narrativa e o envelhecer.

PALAVRAS-CHAVE: Velhice. Narrativa. Cinema.

ABSTRACT: This paper discusses issues related to old age, having as the main reference the documentary $O$ fim e o princípio (2005) by the filmmaker Eduardo Coutinho. The documentary includes a set of seemingly random stories told by elderly. The space chosen by the director to "collect" these reports is the Paraíba. We start this production to write another plot involving reflection between narrative and the acting of aging.

KEYWORDS: Aging. Narrative. Cinema..

\section{INTRODUÇÃO}

Pensar uma imagem de velhos no Nordeste brasileiro através de um documentário, gênero fílmico geralmente pouco analisado pelos historiadores - possivelmente pelo caráter mais ou menos comercial que esses filmes terão na história do cinema mundial é uma maneira de mostrar uma dada realidade de forma "nua e crua", sem falseamento e sem manipulação, pois ali está "a verdade tal qual ela é”, ao contrário dos filmes ficcionais, que constroem e falseiam os fatos apresentados, de acordo com as necessidades de quem os produzem.

Para começo de conversa, este texto se inspira nas reflexões de Manuela Panafria sobre a interpretação de filmes(2009). Ela diz que a análise de um filme pode ser entendida como a sua decomposição, observando o enredo e o cenário, por exemplo, e/ou a própria 
análise da obra. Não há metodologia universal quando lidamos com a produção fílmica, o que se pode fazer é explicar e interpretar elementos de uma dada produção. Recorremos ao seu método quando consideramos $O$ fim e o princípio como um relato do tema velhice suscitando questões que promovam intersecções com a memória.

Os filmes, independentemente do gênero, são fontes importantes para a compreensão, dentre outros aspectos, de como, por exemplo, o Estado, bem como outras instituições, utilizam o grande poder de difusão de ideias e comportamentos dos meios de comunicação para construir e propagar acontecimentos de conjunturas e de estruturas. Mas, e os filmes documentários, como ficam nessa história de apresentar "verdades" e representar realidades? Antes de tentar responder a essa pergunta, através da análise do documentário $O$ fim $e$ o princípio, lançado no ano de 2005 pela VideoFilmes e dirigido pelo documentarista Eduardo Coutinho $^{1}$, vamos refletir um pouco sobre uma outra questão: o que é documentário?

A década de 1960 foi marcada por uma elevada consciência histórica, política e social por parte dos cineastas daquele período, fato que pode ser percebido nas produções dos documentários produzidos na época, que tinham como foco questões mais coletivas, e os indivíduos representavam uma espécie de síntese da experiência de grupos. São desse período documentários vistos hoje como clássicos, a exemplo de Aruanda (NORONHA, 1960), Garrincha, alegria do povo (PEDRO DE ANDRADE, 1963), O país de São Saruê (CARVALHO, 1971), dentre outros. É importante destacar que

na maioria desses filmes, estava expressa uma forte preocupação social que, imbuída de um espírito iluminista, missionário, marcante na época, fazia com que os cineastas acreditassem na mudança da sociedade em decorrência de suas atuações. É nesse contexto que surge o "tipo sociológico", definido por Jean Claude Bernardet (HOLANDA, 2006, p. 2).

Vários estudiosos desse gênero no Brasil acreditam que a forma de se fazer documentários no país muda na primeira metade da década de 1980, quando Eduardo Coutinho produz Cabra marcado para morrer. Nele, os dramas pessoais estão no primeiro plano, mas, mesmo assim, o contexto sociopolítico não fica ausente da história apresentada. Provavelmente, essa foi a grande máxima do diretor ao mostrar que, não apenas na ficção, mas também em documentários, as pessoas estão, igualmente, encenando, representando a si mesmas.

\footnotetext{
${ }^{1}$ Eduardo Coutinho nasceu em maio de 1933, em São Paulo. Começa a estudar cinema depois de um evento promovido pelo MASP, em 1954, quando passou a se interessar por roteiro. Foi para Paris estudar direção e montagem com o dinheiro que ganhou num concurso de televisão respondendo perguntas sobre Charles Chaplin. Um dos documentaristas mais importantes do Brasil, Coutinho foi assassinado pelo filho em fevereiro de 2014.
}

Oficina do Historiador, Porto Alegre, EDIPUCRS, v. 11, n. 1, jan./jun. 2018, 
Nos trabalhos produzidos por Coutinho ${ }^{2}$ são apresentadas diversas manifestações de comportamentos, e as pequenas histórias dos personagens nos colocam diante de uma simbiose formada por meio de um princípio normativo pré-estabelecido e das possibilidades de interpretação de cada personagem. Em $O$ fim $e$ o princípio, por exemplo, vários personagens trarão diferentes pontos de vista sobre a vida e a morte, o amor e a velhice. Em suas obras, Coutinho buscou conhecer ao invés de mudar o mundo com os filmes que produziu.

Bernardet e Ramos (1988) mostram as dificuldades para conceituar o "filme documentário". Esses autores definem esse gênero como "filmagens de algo que aconteceria independentemente da realização de um filme" formulando, inclusive, uma situação hipotética: "Por exemplo: um jogo de futebol ocorre independentemente de ser filmado ou não, ao passo que, no caso de um filme de ficção, o que é filmado é preparado e representado especialmente para a filmagem" (BERNARDET; RAMOS, 1988, p.36).

É necessário estar ciente de que, mesmo que os eventos ou acontecimentos registrados pela câmera no decorrer das filmagens de um documentário não sejam, em tese, planejados e/ou representados, o filme será sempre um produto resultante de várias manipulações que definirão sua forma final. Através da escolha de enquadramentos de câmera, análise e seleção de imagens, montagem, inserção de entrevistas, músicas e outros elementos que vão compor a trilha sonora, os documentaristas "constroem uma interpretação da realidade" (BERNARDET; RAMOS, 1988, p. 37). Existe, ainda, a possibilidade de se falsificar determinada realidade que se pretende documentar.

Em O fim e o princípio, a forma que Coutinho buscou para representar a realidade e convidar o espectador a refletir sobre a velhice e a morte foi por meio das lembranças dos velhos que moram em São João do Rio do Peixe, no estado da Paraíba.

Lembrar é uma forma de "revisitar" o passado. O passado, conservando-se na memória de cada ser humano, aflora a consciência na forma de imagens-lembranças. Não se pode esquecer que essas lembranças vão depender do relacionamento com a família, a classe social, a escola, as tradições religiosas, a profissão, enfim, com os grupos de convívio e os grupos de referência peculiares a esse indivíduo. O maior número de nossas lembranças vêm quando nossos pais, amigos ou outras pessoas as provocam, ou melhor, fazem com que elas aconteçam e, na maioria das vezes, lembrar não é só reviver, mas refazer, reconstruir, repensar com imagens e ideias de hoje, as experiências do passado. Bosi (1994) argumenta

${ }^{2}$ Edifício Master (2002), Santo Forte (1999), Jogo de Cena (2007), dentre outros. 
que "cada geração tem, de sua cidade, a memória de acontecimentos que permanecem como pontos de demarcação em sua história" (p. 418).

\section{MUDANDO O RUMO DA PROSA...}

Manhã muito quente pelos confins da Paraíba. À medida que o carro avança na paisagem seca, solo arenoso e pedregoso, cores nada vibrantes. $\mathrm{O}$ verde, que geralmente demarca as estradas, não fica muito nítido por ali. Das árvores, restaram os galhos desprovidos quase totalmente do verde das folhas. Estrada adiante não se vê nenhum animal campestre. Terrenos separados por cercas de varas secas e arames. Casas que parecem abandonadas, mas quando nelas se penetra, percebe-se, além dos velhos moradores, mobílias, arreios de animais e quadros de santos e santas nas paredes, não sendo esses últimos apenas uma forma de se fazer perceber a devoção das pessoas pelos santos católicos, visto que a religiosidade é, de certa forma, o "temer" a Deus - que será algo bastante presente nos discursos dos personagens que aparecem no documentário.

Eduardo Coutinho, acompanhado de sua equipe, está em busca de lugares na Paraíba para dar forma a um projeto: ouvir histórias de vida da população mais velha do interior da Paraíba. A equipe viajava sem nenhum roteiro de filmagem ${ }^{3}$. Eles tinham apenas quatro semanas e a única pesquisa prévia feita era a da hospedagem. A primeira cidade visitada foi São João do Rio do Peixe, havendo a possibilidade de, caso não encontrassem situações e depoimentos ideais para filmagem, visitar outras cidades do sertão da Paraíba, a exemplo de Cajazeiras e Patos, como mencionado pelo diretor no documentário.

Coutinho entrou em contato com algumas pessoas da região esboçando o objetivo do filme. Desse modo, chegou até Rosilene Batista de Sousa, a Rosa, que mora no Sítio Araçás, povoado com mais de oitenta famílias da zona rural de São João do Rio do Peixe, a seis quilômetros da zona urbana. Rosa é professora e voluntária da Pastoral da Criança. A equipe chegou sem avisar, por falta de telefone na casa da voluntária. É aqui que a história começa. Rosa aceita ajudar a equipe na aventura em busca de relatos que, como diz Coutinho, sejam "histórias de pessoas que tenham uma vida".

Trata-se de um contato com a experiência, conforme colocava Walter Benjamin, isto é, aquilo que atravessa o sujeito deixando marcas e vestígios. A experiência tem relação direta

\footnotetext{
${ }^{3}$ É importante destacar que a forma de produção dos documentários de Eduardo Coutinho chama atenção por algumas nuances, a exemplo de sempre aparecer o diretor e a equipe de filmagens em cena, deixando ser percebido o processo de produção do filme, além da ausência de um roteiro fechado para produção do documentário. O fim e o princípio é um trabalho no qual podemos ouvir mais a voz e a respiração de Coutinho e, em alguns momentos, ele deixa de ser o entrevistador e passa a ser o entrevistado.
} 
com deslocamentos, com viagens, com aventuras, mas, também, tem relação com a velhice. Ora, num texto curto e inquietante, Benjamin (2012) faz uma reflexão que podemos trazer para o documentário em questão. Em breves palavras, há um ancião em seu leito de morte, passando um ensinamento para os filhos: dizia que eles plantassem sementes com um trabalho duro e esperassem a próxima estação. Os filhos obedeceram, mas nada viram acontecer; após o plantio, foi necessária a mudança das estações para que as sementes se tornassem bonitas vinhas até chegar a hora da colheita. A questão que move o texto não é de trabalho, mas, sim, a transmissão de experiências. Eis o objetivo de Eduardo Coutinho: ouvir histórias de vidas marcadas por experiências.

As histórias, ao saírem da memória, podem ganhar materialidade discursiva através da narração - outro conceito trabalhado por Benjamin e ligado ao transmitir e, sobretudo, ao morrer. Quando faz essa reflexão, Benjamin convida o pesquisador a pensar algumas questões do seu ofício. O caráter da transmissão nos seus escritos é uma delas. Transmissão dita como tradição, algo que se passa para outros. Mas há uma constatação: a experiência (a transmissão de geração para outra) está em crise e a solução seria pensar em técnicas de experiência porque essa prática está desaparecendo do cotidiano e nossa condição de vida nos convida a uma aceleração dos saberes. Com isso, vai se perdendo o respeito pelo que vem de longe, pois é o que vem do longe espacial e temporal que traz consigo as experiências. Mesmo sabendo que a forma de perceber o mundo mudou, e continua mudando, assim como as relações e os tipos de produções, é preciso sempre lembrar e perceber a importância da experiência.

Defendemos, inclusive, que a experiência está relacionada à atividade do pesquisador das humanidades devido ao seu caráter de efemeridade, de registro do que se passa pelo exercício da narrativa. A prática da experiência está ligada à uma temporalidade e à uma comunidade, vem do passado, do que ocorreu, e é possível pela linguagem. Assim, é preciso investir em experiência nas nossas escrituras, de modo a esclarecer as vivências do que se transmite, porque viver pressupõe, antes de tudo, um contar. Semelhante às vidas capturadas pelas câmeras da equipe de Coutinho, existem porque narram, porque contam e se contam através das experiências da vida. E, ao buscar os relatos de homens e mulheres velhas do ermo sertão do Nordeste, onde muitas relações amorosas aparentam ser como a paisagem, ora com um suave e breve verde, ora cinza, empoeirada e de solo seco, Coutinho contribui para que os depoentes rememorem o passado e reflitam sobre o existir, bem como o morrer.

O fim e o princípio se aproxima da experiência por um duplo caminho. Primeiro, o destaque conferido à fala de vários indivíduos, idosos na maioria, razão norteadora do documentário, porque são especialmente os mais velhos, devido aos deslocamentos da vida, 
que adquirem acontecimentos variados e, por ocasião da filmagem, os transformam numa narrativa da experiência. Segundo, pela proposta do filme que é, propriamente, uma aventura. Apesar de Coutinho conhecer o estado da Paraíba desde a década de $1980^{4}$, a viagem se dá sem saber muito o que pode acontecer - lembrança evidente do retorno de Ulisses para Ítaca na conhecida narrativa épica de Homero. É uma aventura feita por narradores-personagens, operada por um diretor que busca por experiências. Logo nas primeiras cenas do documentário, Coutinho explica que a equipe está no sertão da Paraíba sem nenhum tema em específico, tampouco uma locação em particular. Eles estão à procura de uma comunidade para ser tema do filme, mas, também, que, caso a comunidade não fosse encontrada, o documentário seria sobre essa busca. O deslocamento, a viagem, o desvio na trajetória dos planos e da vida traz o convívio com o inusitado, com o outro, com as histórias de dores e alegrias, histórias de gente que chega, vem de longe e senta num terraço ou numa rede e se deixa atravessar pelo contar do Outro.

Contudo, há outras questões que se colocam. Ora, por que um renomado documentarista se lança sobre a Paraíba e busca histórias contadas por pessoas velhas operando perguntas que rondam entre o sentido da vida e o pensar sobre a morte? Por que um diretor precisa criar um filme com essas histórias de muitos passados? Como se dão os relatos sobre a vida na velhice? Indivíduos com rostos marcados pelas alegrias e angústias da vida, de um Nordeste pobre, mas não miserável e que, mesmo com uma paisagem árida e infértil, como a que geralmente é mostrada em filmes sobre a região e que é repetida em $O$ fim $e o$ princípio, acolhe jovens e velhos, que, entre lembranças e esquecimento, almejam, pelo menos, vivenciar os ciclos das colheitas que a vida proporciona.

A narrativa que inaugura essa viagem em busca do tempo perdido de uns passados é a de Maria-vó, avó de Rosa, cujo foco da fala é o trabalho, a fome e a miséria. Ao ser perguntada pela neta sobre a seca de 1915 - que deu nome ao conhecido romance de Raquel de Queiroz - ela dispara: “foi ruim, nós sofremos... muita fome. Minha vida era trabalhar nas carreiras, trabalhando [...] só tinha uma horinha na noite que eu dormia um soninho. Eu me acordava de madrugada... [para] bater algodão".

Após a doçura de Maria-vó, Rosa leva a equipe para o Riachão dos Bodes, onde vive Dona Rosa que, ao ser indagada sobre o medo da morte, afirma viver no mundo até quando Deus quiser, e diz não querer conversar mais com a equipe. Coutinho e a equipe voltam para Araçás. Como nos mostra Lins (2004), “É essa concepção de cinema que faz Coutinho

${ }^{4}$ Época das filmagens do documentário Cabra marcado para morrer. 
desconsiderar a feitura de roteiros, prática que, para ele, desvirtua esforços e corrói o que mais preza no documentário: a possibilidade de criação de algo inesperado no momento de filmagem, e só ali” (p. 11).

O Nordeste e, mais especificamente, o nordestino, bastante apresentados e representados no cinema e nas novelas brasileiras, são apresentados em $O$ fim e o princípio sem a obrigação de provar nada. Ou seja, o filme propõe uma relação com o espectador no que tange ao assunto abordado, sendo aquele que assiste o responsável por procurar dar sentido ao filme a partir do que está sendo narrado, tanto pelo diretor quanto pelos personagens.

De volta ao sítio Araçás, somos apresentados a Mariquinha, uma senhora bem humorada que, após a explicação de Rosa sobre a produção do filme, diz, em tom de brincadeira: "é mermo é? Uma obra dessa, uma véia caduca como eu". E, da sua fala, se editou o seguinte: “o meu nome é Maria Ambrosina Dantas, mas o povo chama eu Mariquinha". Parece preferir seu nome ao apelido porque "apelido não vale nada. Se rezar uma pessoa por apelido não serviu aquela reza". Parece que os idosos da comunidade não gostam de apelidos, preferem mesmo é o nome, ou de batismo ou um diminutivo acolhedor, simpático. O uso do nome é importante, inclusive, para as orações, e Marquinha entende disso porque reza de tudo "peito aberto, dor de cabeça, dor de dente, olhado, quebranto, ventre caído, triação, espinhela caída [...]". Mas, ao ser perguntada sobre as palavras da reza: "Não digo não. Ninguém ensina não [...]”. Afirma, ainda, que sempre deu certo, "toda vida e tudin [sic] só vem para minha casa". Mariquinha não recebe pelo trabalho, "nunca recebi nada, que reza não se vende".

$\mathrm{O}$ diretor mostra que, mesmo com todas as mudanças trazidas pela modernidade, a exemplo do uso de energia elétrica, o uso de eletrodomésticos, há carros e motos circulando ao lado de cavalos e jumentos puxando carroças, etc. Geraldo, também conhecido como Vigário, diz, em um trecho do documentário, que prefere "andar a cavalo a andar de moto, bicicleta ou carro". Vigário diz, ainda, desconhecer alguns tipos de eletrodomésticos, a exemplo do rádio: "nunca tive rádio. Não sei o que é rádio". Esses fatos contribuem para que o espectador perceba que o recorte temporal nada mais é do que uma abstração da ciência. $\mathrm{Na}$ realidade mostrada pelo diretor, para os moradores daquela região, o tempo não se classifica; ele é vivido das formas que são possíveis e com o que a vida oferece. E, entre esse "moderno" e o "arcaico", a prática da reza, atividade que há desde o Brasil Colônia, ainda existe no âmbito cultural do Nordeste e, especificamente, na cidade de São João do Rio do Peixe. 
O "dedo de prosa" com Mariquinha prossegue e Eduardo Coutinho questiona se ela tem medo da morte, ao passo que ela responde: “eu tenho muito medo [...] mas é o jeito, né?". Ela chora e, depois, diz que "a nossa vida é um parafuso, só quem distorce é Jesus no dia que Ele quiser".

Inclusive, em momentos diferentes, dois entrevistados falam que, quando Coutinho retornar a São João do Rio do Peixe para exibir o documentário, eles não estarão mais vivos para assisti-lo.

Tudo o que é natural, geralmente é bem aceito. Abre-se uma exceção para a morte. A morte é tão estranha quanto íntima para nós; nem totalmente estranha nem puramente pessoal. Nessa medida, nossa relação com ela assemelha-se à relação com as outras pessoas, que são, da mesma forma, tanto companheiras quanto estranhas [...]. Por estar assim entrelaçada com nossas vidas, a morte pode torna-se menos assustadora, menos uma força ameaçadora que simplesmente está em campo para acabar conosco (EAGLETON, 2005, p. 284).

A pergunta sobre a morte está diretamente associada à velhice. Encará-la, a Sociologia não nos deixa dúvida, ainda é etapa difícil para os seres humanos. A constatação de que a vida não é eterna ocasiona um certo desconforto. Não nos acostumamos com a ideia de que a vida, essa estranha hospedaria, lembrando dos versos de Mário Quintana, tanto nossa como dos nossos próximos, não é perene e o resultado disso é uma pavoneamento de narrativas apaziguadoras como as noções de que essa vida é uma passagem. A vida não termina nesse plano, há um recomeço, ou, numa perspectiva mais católica, haveria um paraíso.

Eagleton afirma que os teóricos dos Estudos Culturais são reticentes sobre alguns temas, dentre eles a morte e o sofrimento. De acordo com o autor, muitas vezes, esquecemos que a morte nada mais é do que uma das estruturas internas da própria existência social.

Nobert Elias, sociólogo da cultura da primeira metade do século XX, estudou a questão da velhice e do morrer. "Na verdade não é a morte, mas o conhecimento da morte que cria problemas para os seres humanos" (2001, p. 11). O problema seria sabermos que vamos morrer. Eis o óbvio da discussão e isso ocorre porque somos seres vivos que, historicamente, construímos a morte como problema.

Essa questão da morte foi estudada pelo historiador Philippe Ariés (2003). Nesse estudo, vemos que a morte é construída histórica e culturalmente devido a modificações que operam com o passar do tempo. Ora, a concepção de morte que atravessa nossa contemporaneidade nem sempre foi vista, sentida, ou praticada da mesma forma. Na Idade Média, dos séculos XII ao século XV, a morte passa a ser relacionada a um individuo, se 
afastando de uma noção de coletivo e se aproximando de uma biografia que levasse em consideração o apego às coisas da vida. $\mathrm{O}$ homem passava a tomar consciência de si mesmo no tocante à efemeridade da vida: a morte passava a ter um aspecto de sofrimento e, como consequência, as sepulturas deixaram de ser coletivas, passando a ser individuais.

A dor da morte se dá por não se saber lidar com a perda do que se tem em vida e a separação com quem se convive. Esse movimento está presente no Romantismo, especialmente na fase do Ultrarromantismo e, nesse momento, com precisão a partir do século XVIII, o moribundo passa a expressar os seus desejos e afetos oralmente, com destaque para momentos antes da morte.

No século XX, esse moribundo também já é um outro indivíduo. É aquele cujo estado de saúde vai se esfacelando com o avanço da idade e, daí, em vez de morrer em casa, é possível morrer no hospital, munido de todos os cuidados - ou não - da medicina. Paralelamente, o luto se torna discreto e se avança às práticas de cremação, denunciando, talvez, um desejo de se afastar de tudo que pudesse restar do corpo.

E esse medo da morte que aparece na fala de Mariquinha pode estar relacionado ao firme apego à vida, sem dúvida relacionado à civilização industrial, e, simultaneamente, desejo de se afastar do seu oposto, a morte. Esse significado do morrer foi, em grande parte, conservado na nossa pós-modernidade - não estamos dizendo que não houve modificações -, de modo que, através dos nossos aprendizados culturais, a morte aparece como problema porque é dela de que nada se sabe. Diferente do homem pós-moderno que tudo quer saber e dizer, da morte há um amontoado de especulações.

Na concepção de Nobert Elias, quando falamos de morte, não está em jogo apenas o óbito, mas a relação de que envelhecer é morrer aos poucos, em grande medida devido ao isolamento e fragilidade de pessoas que estão incluídas numa conceituação social denominada de “idosas". Possivelmente, é por isso que dona Mariquinha compara o viver às voltas dadas por um parafuso. Chegará um momento em que ele não terá mais movimento, e tudo acaba ali, naquele momento.

Uma das provocações trazidas pelo documentário é que esses idosos, que, em breve, encontrarão uma morte física, já estariam vivenciando uma morte social, pois vivem em um local "quase abandonado", onde só é possível chegar quando não se busca nenhum lugar, ou o não lugar, na perspectiva de Augé (1994).

Beauvoir (1976), ao contrário, não faz a relação entre a morte e velhice, deixando claro que isso é algo característico do século XIII, quando velhice era considerada uma doença e, caso o indivíduo não se tratasse, “morreria de velhice”. De acordo com a autora, a 
velhice é diferente para cada pessoa e sofrerá influência da classe social, da região em que a pessoa vive, da família, da saúde, dentre outras causas. Entretanto, ao contrário do que alguns autores afirmam, a velhice nada mais é do que uma outra fase da vida e, além de ser um fator biológico, é um fato cultural.

Mariquinha vive sozinha. É viúva há mais de quarenta anos e a morte do marido trouxe felicidade à sua vida. Isso porque “ele era um cachaceiro e judiava com eu”. Juntos, tiveram catorze filhos, mas apenas dois sobreviveram. Uma filha mora perto dela e o outro vive bem longe da sua cidade, em Porto Velho, Rondônia. Nesse momento, ela se emociona, mas parece não querer esboçar tristeza: "só vejo de cinco em cinco anos" e, ao ser indagada se sente falta dele, afirma: "saudade muita".

Ao contrário de dona Mariquinha, seu Leocádio, "metido a sabichão porque sabe ler", é solteiro e vive sozinho. "Preferi ser livre", afirma. Dentre as coisas de que mais gostava de fazer, quando jovem, conforme informa, era ler a Bíblia, ler jornais com notícias sobre a guerra. Duas pessoas que vivem na mesma região e que, talvez, a única similitude seja a velhice, pois a solidão, pelo que pode ser percebido, é vivenciada de forma diferente por ambos.

Não sabemos o motivo pelo qual Mariquinha vive sozinha. Mas isso permite refletir que muitos idosos são deixados de lado pela família e, às vezes (não é o caso de Mariquinha), são esquecidos por parentes e mesmo os não abandonados sofrem de solidão. Acaba ocorrendo um distanciamento das pessoas jovens em relação às pessoas velhas que se deve à "nossa incapacidade de dar aos moribundos a ajuda e afeição de que mais que nunca precisam, [...], exatamente porque a morte do outro é uma lembrança de nossa própria morte" (ELIAS, 2001, p. 16).

Envelhecer é uma experiência vista por muitos como algo que precede a morte. Morrer e envelhecer estão intimamente conectados na cultura ocidental. Mas fica a questão: o que é envelhecer? Numa conceituação prévia, se trata de um momento da vida (tida como o último) vivenciado por alguns sujeitos que chegam até ela. Mas há tramas bem mais intrigantes dentro desse tema. Violências, biopolítica, subjetividades, solidão, doenças, sensibilidades, saudades, memória são temas comumente associados à velhice.

A questão da velhice não deve ser pensada como eminentemente cultural. Há um fator biológico que contribui nas experiências do envelhecer, dado que os corpos humanos sofrem transformações metabólicas, funcionais, físicas e fisiológicas. Geralmente, são características que atravessam inúmeros indivíduos, mas são sentidas de maneira heterogênea por questões relativas à sociedade e à cultura. É, sobretudo, nessas esferas, social e cultural, que a velhice é 
moldada, construída, pensada, dada a ler instituindo e modificando gradativamente quais elementos passam e deixam de constituir o "estar idoso".

Estereótipos relacionados ao velho, tais como improdutivo, decrépito, isolado, já trocaram lugar de outras maneiras de refletir o velho como sinônimo de sabedoria. Tudo isso obedecendo a relações de saber-poder características de interesses de determinados momentos. Ultimamente, com o aumento do envelhecimento da população, o Estado passou a refletir essa etapa da vida de modo a geri-la. É importante perceber, ainda, que, se esses velhos não produzem "mais nada", já produziram em um passado não tão distante, sendo "recompensados" com a aposentadoria. Alguns outros são aceitos pelas famílias apenas por um "incremento" na renda familiar, vivendo "da caridade de quem os detesta".

\section{CONSIDERAÇÕES FINAIS OU O PRINCÍPIO DO FIM}

Há um gerenciamento dos corpos envelhecendo e a tentativa de torná-los úteis no corpo de uma tecnologia de poder que procura pensar novas atividades para o ser velho. Eis a biopolítica - conceito formulado por Michel Foucault (2012) ao estudar a modernidade, sobretudo por modificações no Estado Moderno no qual o rei deixa de lado a ideia de poder, de matar os corpos que aparentemente nada valem para o Estado e passa a construir a noção de poder sobre a vida, poder para gerir e produzir a vida.

As noções acerca da velhice passam a permear uma série de discursos aparecendo em filmes, documentários (como o que tomamos para refletir aqui), literatura, músicas. Ney Matogrosso subiu ao palco e cantou na música Lema: "Não vou lamentar / a mudança que o tempo traz, não / o que já ficou para trás / e o tempo a passar sem parar jamais / já fui novo, sim / de novo, não / ser novo pra mim é algo velho / quero crescer / quero viver o que é novo, sim / o que eu quero assim / é ser velho". Em direção contrária, Teixerinha lamentou, em Quando a velhice chegar: Quando a velhice branquear meus cabelos / As minhas forças chegarão ao fim" e "Hoje sou novo, amanhã sou velho / Depois de velho se perde a paciência”. Duas músicas, duas versões distintas: uma positiva, marcada pela chegada de uma nova etapa da vida, e outra negativa, posto que improdutiva. Eis diferentes apropriações, reinterpretações e ressignificações da velhice.

É curioso perceber que as atuais discussões sobre o envelhecimento começam a surgir mais intensamente após os anos 2000 e o documentário em análise é de 2005. Nesse meio termo, em 2002, o Brasil pôde assistir a um dos enredos da novela Mulheres Apaixonadas, de Manoel Carlos, que causou fúria em parte da população. Era a história de Leopoldo (Oswaldo 
Louzada) e Flora (Carmem Silva), maltratados pela neta Régis (Regiane Alves). Um ano depois era criado o Estatuto do Idoso no país. Isto é, na época em que o documentário foi pensado estava ocorrendo uma série de discussões acerca do papel dos idosos na sociedade e dos problemas relativos à essa fase etária da vida. Soma-se a isso a questão demográfica com incentivos científicos-tecnológicos estendendo-se desde a indústria alimentícia até a farmacêutica, favorecendo a expectativa de vida.

Assim, a partir de uma série de modificações da contemporaneidade, a velhice parece sair do seu local de silêncio e adentra a ordem do discursos, ganhando visibilidade, o que permitiu, inclusive, ocupar as universidades, sendo pensada e questionada em projetos de pesquisa que visam perceber, em grande medida, a qualidade de vida e a teia discursiva que constrói os modelos de velhice.

No decorrer do documentário, nos deparamos com várias histórias. Histórias de saudades, de trabalho, de infância na enxada, de amor, de tristezas, histórias que, de repente, vêm de fragmentos da memória, que, por um segundo, relampeja e se eterniza na filmagem para, depois, morrer novamente nas teias do esquecimento. Inevitavelmente, a memória é um outro patamar na análise desse documentário.

Fala-se muito em memória, nos mecanismos para conservar lembranças, no caráter destrutivo da memória. Igualmente, tecem-se reflexões do que consistiria a produção historiográfica ao eleger a memória como fonte. Nesse sentido, circulam discussões sobre acumulação da memória, uma soma de eventos. Mencionam-se, igualmente, uma memória da psicanálise, uma memória da filosofia, uma memória dos acontecimentos traumáticos. Fala-se da memória de história de vida. Mas a memória é sempre uma recriação, uma reformulação do acontecido marcado pelo presente daquele que lembra; a arqueologia da cena é revisitada, revista, limpa ou deformada, de acordo com o discurso que se queira levantar.

É pertinente destacar que, no século XIX, Nietzsche (2003) analisava os usos e valores da memória. Nietzsche via negativamente o acúmulo da memória, em crítica ao historicismo, porque poderia causar uma paralisia do presente. A análise construída pelo autor é extraída da Segunda consideração intempestiva, que tem como subtítulo Da utilidade e desvantagem da história para a vida e defende que se deve, sobremaneira, saber esquecer; dito de modo mais claro, não se deve acumular ventos de memória. Tal empreitada causaria um acúmulo que poderia ser prejudicial à vida.

Mas o que ocorre quando a memória se torna história? A indagação procura refletir um lado oposto ao comumente analisado de que a memória é alimento para a história. A rota 
traçada deseja pensar memória a partir da ideia de memória coletiva cunhada por Maurice Halbwachs (2004):

Nossas lembranças permanecem coletivas e nos são lembradas por outros, ainda que se trate de eventos em que somente nós estivemos envolvidos e objetos que somente nós vimos. Isto acontece porque jamais estamos sós. Não é preciso que outros estejam presentes, materialmente distintos de nós, porque sempre levamos conosco e em nós certa quantidade de pessoas que não se confundem (p. 30).

Nesse sentido, a memória, mesmo a mais particular, está relacionada a um grupo. Ainda que esse indivíduo traga em si lembranças, isto só ocorre, ele lembra, porque houve uma interação com a sociedade. A lembrança é construída a partir de imagens, signos, grupos e instituições que formam um contexto permitindo diferentes elementos na constituição das lembranças. Assim, a memória de cada um dos entrevistados é relampejos de memórias de alguns indivíduos com os quais outrora travou relação. Lembranças, portanto, são emitidas de um singular, mas, por consequência de um plural, dado às significações culturais mais amplas que as permeiam.

É importante perceber que o audiovisual, independentemente do gênero, nos dá acesso a um fato que, mesmo com toda a proximidade e referência ao mundo histórico, é a visão do diretor a respeito daquela realidade mostrada. Sendo, ainda, o documentário um "lugar de discurso" - assim como todo documento, nos traz um ponto de vista sobre uma realidade assim como um lugar de memória, materializando, de forma simbólica, elementos de identidade social e cultural de um dado grupo. Eduardo Coutinho, ao visitar a Paraíba em busca de uma história para ser contada em $O$ fim e o princípio, através dos depoimentos dos entrevistados, foi fiando uma colcha de memórias, de diferente cores, com momentos alegres e tristes de uma comunidade que está unida não apenas por morar no mesmo povoado, mas pelos fios das lembranças de um passado vivido, apesar de todas as limitações, traumas, dores, amores e desamores, para eles, talvez porque, diante de tudo, existe a relação de afeto entre todos que ali moram e que ajudaram Coutinho/Ulisses em uma odisséia (com impressão) de finitude.

\section{REFERÊNCIAS BIBLIOGRÁFICAS}

AGRA DO Ó, Alarcon. Velhices Imaginadas: Memória e envelhecimento no Brasil (1935, 1937, 1945). Campina Grande: Editora da Universidade Federal de Campina Grande, 2010.

ARIES, Philippe. História da Morte no Ocidente. Rio de Janeiro: Ediouro, 2003. 
ARUANDA. Direção: Linduarte Noronha de Oliverira. Brasil, 1960. Documentário. 22 minutos.

AUGÉ, Marc. Não-lugares: introdução a uma antropologia da supermodernidade. Campinas: Papirus, 1994.

BEAUVOIR, Simone de. A velhice. Rio de Janeiro: Nova Fronteira, 1976.

BENJAMIN, Walter. Obras escolhida volume 1: Magia e técnica, Arte e Política. São Paulo: Brasiliense, 2012.

BERNARDET, Jean-Claude. Cineastas e imagens do povo. São Paulo, Companhia das Letras, 2003.

; RAMOS, Alcides Freire. Cinema e História do Brasil. São Paulo: Contexto, 1988.

BOSI, Eclea. Memória e sociedade: lembrança de velhos. São Paulo: Companhia das Letras, 1994.

CABRA MARCADO PARA MORRER. Direção: Eduardo Coutinho. Brasil, 1984. Biografia. Documentário. 119 minutos.

EAGLETON, Terry. Depois da teoria. São Paulo: Brasiliense, 2005.

ELIAS, Nobert. A solidão dos morimbundos. Rio de Janeiro: Jorge Zahar, 2001.

FOUCALT, Michel. História da sexualidade volume 1: a vontade de saber. São Paulo: Martins Fontes, 2012.

GARRINCHA, A ALEGRIA DO POVO. Direção: Joaquim Pedro de Andrade. Brasil, 1963. Documentário. 60 minutos.

HALBWACHS, Maurice. A memória coletiva. São Paulo: Centauro, 2004.

HOLANDA, Karla. Documentário brasileiro contemporâneo e a micro-história. Fênix Revista de História e Estudos Culturais, v. 1, 2006.

LINS, Consuelo. O documentário de Eduardo Coutinho: televisão, cinema e vídeo. Rio de Janeiro: Jorge Zahar, 2004.

MOURÃO, Maria Dora; LABAKI, Amir (Orgs). O cinema do real. São Paulo: Cosac \& Naify, 2005.

NIETZSCHE, Frederick. Segunda Consideração Intempestiva: da utilidade e desvantagem da história para vida. Rio de Janeiro: Relume-Dumará, 2003.

O FIM E O PRINCÍPIO. Direção: Eduardo Coutinho. Produção: Maurício Andrade Ramos, João Moreira Salles e Eduardo Coutinho. Fotografia: Jacques Cheuiche. Edição de fotografia: Jordana Berg. Brasil: 2005. Documentário. 118 minutos.

O PAÍS DE SÃO SARUÊ. Direção: Vladimir Carvalho. Brasil: 1971. Documentário. 80 minutos. 
PENAFRIA, Manuela. Análise de filmes - conceitos e metodoligias. Disponível em: http://www.bocc.ubi.pt/pag/bocc-penafria-analise.pdf. Acesso em: 18 mar 2017.

XAVIER, Ismail. Documentário e afirmação do sujeito - Eduardo Coutinho na contramão do ressentimento. In: CATANI, Afrânio Mendes; GARCIA, Wilton; LYRA, Bernardete (Orgs). Estudos Socine de cinema: Ano IV. São Paulo: Panorama, 2003.

ARTIGO ENVIADO EM: 03/07/2016 ARTIGO ACEITO PARA PUBLICAÇÃO EM: 31/03/2017 